\title{
'Less bureaucracy' pledge for Italian space agency
}

\section{IMAGE UNAVAILABLE FOR COPYRIGHT REASONS}

Up and away: the Parkes multibeam device is hoisted towards the telescope's focus cabin.

\section{Multibeam survey sweeps galaxies}

[PARKES, AUSTRALIA] The 64-metre telescope at Parkes, Australia, began last week the first 'blind, all-sky' survey of radio galaxies in the southern skies using a unique multibeam device that gives a wide-angle view, greatly increases sensitivity, and will shorten the survey from several decades to a few years.

The multibeam device was commissioned last week by Australia's science minister, Peter McGauran. The cost of A $\$ 3$ million (US $\$ 2.3$ million) was augmented with about $£ 200,000$ (US $\$ 320,000$ ) from Britain for equipment from the Jodrell Bank telescope. The device provides simultaneous observations of 13 separate radio sources in the $21-\mathrm{cm}$ wavelength of neutral hydrogen at two polarizations.

Astronomers claim that the device is "a thousand times faster than anything before and anything envisaged for the next five years". The survey will detect galaxies out to a redshift of $10,000 \mathrm{~km}$ per second, and its sensitivity for discovering pulsars has been increased fivefold.

Three previously unknown galaxies were found by the multibeam in its first few days, one appearing from behind the equator of the Milky Way. The project leader, Lister Staveley-Smith, says this proves the instrument's capabilities to receive signals through regions where absorbing matter is densest.

Parkes, first brought into service in 1961, has now received two major upgrades to extend its flexibility and working life. The first, financed by the US National Aeronautics and Space Administration, involved installing a larger cabin at the focus of the altitude-azimuth mechanism to allow for the fast change of receivers.

PeterPockley
[ROME] Italy's space agency, ASI, started operating this month under new rules which, say agency officials, will allow it to run much more smoothly. The reform follows several years of chaos and crisis during which funding was held back from space scientists while huge debts were run up to meet national and international commitments.

The new rules were approved last month by the research minister, Luigi Berlinguer. They create for the first time a science directorate within the agency. The head of the science directorate will report directly to the agency's new president, Sergio De Julio, although the heads of the technical, applications and administration directorates will report to the director general, Giovanni Scerch.

"This move was necessary because research requires a much less bureaucratic approach," says De Julio, who took office last autumn. He is a professor of engineering at Calabria University and was formerly a member of parliament.

For the past six years, Italy's space scientists have experienced lengthy delays, often lasting for years, in obtaining promised funds for research projects. Not only has this been an obstacle to the effective running of national research programmes, but it has also been embarrassing in international circles. In the European Space Agency (ESA), for example, Italy has developed the reputation of being an unreliable partner for having delayed or reneged on agreements essential to international programmes (see Nature $373,467 ; 1995)$.

Since its creation in 1988, ASI has been plagued with management problems - at times giving rise to charges of corruption and financial difficulties. But De Julio points out that ASI has made considerable progress in controlling its debts through bank loans and internal savings. One decision was not to start any new programmes in 1997. De Julio describes this as "a very painful process which I do not wish to repeat", but says it was necessary to help repair the agency's battered credibility within the Italian parliament, which has to approve its annual budgets.

The new rules create a more powerful executive within ASI, simplifying the strategic and financial planning of research. Advisory committees have previously wielded strong influence over detailed planning, while external financial controllers decided what constituted basic research - which must by law receive 15 per cent of ASI's total budget. That left scientists frustrated at decisions made.

De Julio says that the agency will focus its spending more strategically than in the past. Immediate priorities will be in areas of prior investment, such as the international space station. "Some would argue that we shouldn't have put so much into the space station," he admits. "But we now have to consider carefully how to use the percentage of free space station usage that our investment has bought." He also plans to introduce more rigorous systems for evaluating ASI-funded research and for promoting the use of research results.

De Julio's efforts have been generally welcomed in the space science community. Giancarlo Setti, for example, professor of astronomy at the University of Bologna, says that ASI should now be able to function more efficiently. In the past, he says, a lack of funding continuity has been "most damaging" for space science programmes. Setti chairs a new scientific advisory committee to the agency, which met for the first time this month.

Pietro Ubertini, head of the space group at the Institute of Space Astrophysics in Frascati, says that he, too, is "optimistic that the new structure will work, and give a strong direction to the agency". As the principal investigator of one of the instruments on ESA's next gamma-ray astronomy mission,

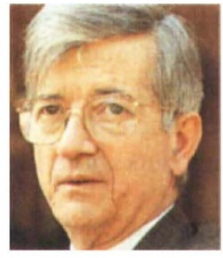

De Julio: aims for strategic focus.

pared to use their budgets to tide us over temporarily," he says. "We have also been able to cope because of our inherent enthusiasm [for the project]."

With the reforms under way, De Julio is now sufficiently confident to have drawn up a five-year plan for the space agency, to start next year. The plan assumes that parliament will agree to increase the annual budget by about 10 per cent in real terms before 2000 .

ESA last week confirmed the appointment of an Italian as its director general (see Nature 386, 104, 1997). Antonio Rodota, an electronics engineer and a graduate of Rome University who is currently director of the space division of the Italian company Finmeccanica, will succeed Jean-Marie Luton, ESA's Council announced. In addition, the contract of Roger Bonnet, director of ESA's science programme, was extended by two years.
Alison Abbott 